\title{
Practical Research on the Application Characteristics and Countermeasures of Online Course Based on MOOC
}

\author{
Qingcai Liu, Xuechun Wan \\ School of Mechanical and Electrical Engineering, Guangzhou Railway Polytechnic, Guangzhou, China \\ Email: 807431278@qq.com
}

How to cite this paper: Liu, Q. C., \& Wan, X. C. (2021). Practical Research on the Application Characteristics and Countermeasures of Online Course Based on MOOC. Open Journal of Social Sciences, 9, 67-74. https://doi.org/10.4236/jss.2021.911006

Received: October 17, 2021

Accepted: November 8, 2021

Published: November 11, 2021

Copyright $\odot 2021$ by author(s) and Scientific Research Publishing Inc. This work is licensed under the Creative Commons Attribution International License (CC BY 4.0).

http://creativecommons.org/licenses/by/4.0/

\begin{abstract}
MOOC is a new means of knowledge dissemination based on the Internet. MOOC can avoid the restrictions on the number of students and learning time and space, facilitate students' autonomous learning anytime and anywhere, and become an assistant for teachers to carry out teaching. MOOC pays more attention to providing students with online learning resources, and its application in teaching has certain limitations or deficiencies. It is not convenient to carry out personalized teaching for specific class requirements, online attendance check and other classroom teaching activities. MOOC does not divide pre class, in class and after class according to teaching requirements, which is not convenient for arranging preview and real-time monitoring of class students' learning progress and academic performance analysis. SPOC based on MOOC not only inherits the advantages of the latter, but also overcomes its limitations. It is more conducive to carry out mixed and personalized teaching for classes, organize classroom online teaching activities, and evaluate class learning progress and situation. According to different characteristics of MOOC and SPOC, it is more appropriate to adopt MOOC for public elective courses and open courses to the society. For specific classes inside and outside school, SPOC is more appropriate, which can make full use of its more balanced function of learning and auxiliary teaching, so as to carry out mixed teaching and improve teaching quality.
\end{abstract}

\section{Keywords}

MOOC, Course Application, Hybrid Teaching, SPOC, Vocational Educational Cloud, Auxiliary Teaching

\section{Introduction}

With the development of digital information technology and the popularity of 
the Internet, $\mathrm{MOOC}$ has developed rapidly all over the world under the guidance of world-class universities. "MOOC" is a transliteration of English MOOC (abbreviation of massive open online courses, also known as MOOCS) (Zhang, 2019), which means large-scale online open courses. It is a new educational and teaching mode. Compared with the previous online open courses, it has stronger scale, openness, sharing and interaction. The rise of MOOC has a profound impact on the traditional teaching mode of higher education in China. Compared with the traditional educational concepts in the past, MOOC teaching shows a wider participation. No matter who, where and when, they can learn the knowledge they want to learn. In the situation of MOOC era, learners can improve their learning efficiency through autonomous learning.

The development of MOOC and other online courses has also brought the emergence of hybrid teaching. Hybrid teaching refers to using online platform and offline method to carry out teaching. This teaching mode organically combines information technology with education. It is a teaching mode under the Internet environment, which is flexible, diverse and targeted. The application of the teaching model can highlight the main position of students, effectively mobilize students' autonomy and enthusiasm, stimulate students' interest, and teachers can give full play to their guiding role in the process of participation. The hybrid teaching mode is mainly implemented in three parts: before, during and after class. By guiding students' autonomous learning, real-time monitoring and feedback on learning, students can deepen their understanding and memory of knowledge (Zhao, 2021). With the combination of teaching and learning, there are a lot of research on hybrid Teaching for various course applications (Peng \& Wei, 2021; Huo, Lv, Bian, \& Guo, 2020; Zhi \& Yang, 2019).

In higher vocational colleges, the construction of online courses has gradually changed from the on campus course platform to the off campus MOOC platform, and teachers have begun to use online courses to implement hybrid teaching. However, they are often not very clear about how to implement hybrid teaching and are still groping. Therefore, based on the author's own experience of using MOOC and SPOC to carry out mixed teaching, this paper discussed the characteristics of MOOC and SPOC and their fit to mixed teaching, which has a certain reference value for teachers and researchers preparing to carry out mixed teaching.

\section{Application Characteristics of MOOC Teaching}

\subsection{No Class Scale and Space-Time Constraints}

The traditional teaching is limited by classroom space and the number of students is limited. The most important feature of MOOC is that it is not limited by the number of class students (Zhang, Zhang, \& Yu, 2020). Thousands of people can learn a course at the same time, which far exceeds the number limit of traditional classes. It can bring learners an experience that breaks through the limitations of time and space. The reason is that the curriculum video is an important 
element of MOOC. It realizes the large-scale dissemination of curriculum resources with the help of information technology, makes its resources break through the limitations of time and space, and allows more people to enjoy more curriculum knowledge resources (Luo, 2021). As long as they have the conditions to surf the Internet, even social people can learn the content they need and update their own knowledge through MOOC, which makes continuous teaching and lifelong learning very convenient. Enterprise technicians can supplement new professional knowledge, science and engineering personnel can learn the knowledge of Humanities and Social Sciences, and retirees can learn calligraphy, art and other knowledge. MOOC provides convenience for learners to obtain more learning opportunities by virtue of network communication. The large-scale opening of curriculum resources enables more people to obtain more and updated knowledge at less cost.

MOOC, as an online course form, is actually a means to realize equal rights in education, which truly provides education for all people without discrimination. Anyone, regardless of gender, age, race, rich or poor, can learn by MOOC. To a certain extent, it can provide any region and anyone with learning opportunities that can fully meet their learning needs, and meet the personalized learning needs of rapid expansion and rapid renewal of knowledge in the information age.

\subsection{Learner Centered Autonomous Learning}

Another notable feature of MOOC is the change of learning style, that is, from the traditional classroom centered on teachers' teaching to students' learning. This is mainly reflected in the learning environment and learning order. Learning environment refers to the synthesis of various supporting conditions to promote learners' development, including physical environment, resource environment and technology environment (Zhong, 2005). MOOC, as a form of network course, can enable learners to break the limitations of time and space in the physical sense and carry out autonomous learning (Zulkifli, Hamzah, \& Bashah, 2020). MOOC meets the concept of open education and realizes the sharing of learning resources. All people with learning needs can use this online education resource. MOOC uses modern information network to share learning resources, so that learners can enjoy a large number of curriculum resources and meet learners' individual needs. In terms of learning autonomy, compared with traditional curriculum teaching, MOOC learners have significant learning autonomy. Facing the rich curriculum resources provided by MOOC, learners can independently choose learning content, arrange learning time, carry out learning activities and master learning progress based on their own needs. The combination of fragmented learning time and open learning forms provides learners with loose and free choices.

\subsection{Function of Teaching Assistance}

MOOC can be a teaching assistant for teachers (Zhang, 2019). In traditional 
classroom teaching, teachers' correcting after-school homework is a time-consuming and laborious work, which is limited by teachers' energy and time. A course will leave 4 to 6 after-school homework in a semester. The number of homework is not enough to achieve the purpose of full practice. There is also a large time difference and poor timeliness from the completion of homework to the completion of teachers' review. For the course in the form of MOOC, each knowledge point is supported by exercise, each chapter is supported by test, and finally the course examination is supported. The amount of homework is far greater than the traditional classroom teaching, and the course training is more sufficient. Moreover, MOOC often adopts more objective questions, which can be automatically reviewed by MOOC platform, which saves teachers' time for reviewing homework and greatly reduces teachers' burden. In terms of timeliness, students can directly choose to complete the corresponding exercises after learning a certain knowledge point independently. At the end of the exercise, students can know the learning results immediately, and the incentive effect is better. Students can find out the omissions and make up the deficiencies in time, relearn and strengthen the weak links.

In terms of after-school learning, traditional classroom teaching usually requires students to preview before class and review after class. But in fact, it is difficult for teachers to grasp students' after-school learning, and a considerable number of students don't want to learn after-school. If you take MOOC as a student's learning task, the system will automatically record each student's learning and automatically calculate related learning score. In terms of performance evaluation, using MOOC as the usual performance of students' learning can realize the quantitative evaluation of students' usual learning, which can not only reduce the burden of teachers' evaluation of performance, but also more accurately reflect students' usual learning and keep in touch with their learning attitude. Because MOOC scores are public, all students can see the scores of other students. MOOC results evaluation can ensure the fairness of performance evaluation to a certain extent and avoid possible problems in educational ethics.

\section{The Deficiency of MOOC in Hybrid Teaching}

Although MOOC has many beneficial characteristics mentioned above and can be used as a learning means for students, there are still some deficiencies in carrying out blended teaching. Because of the complete open nature of MOOC, the number of learners of a course is often large. Therefore, it is inconvenient to adopt MOOC in hybrid teaching for a class of dozens of students.

Classroom teaching generally has the concepts of before, during and after class. Students are required to preview what they want to learn before class. During class, teachers explain the learning content, and carry out teaching activities such as attendance check, questioning and discussion. Homework will be left for students to complete after class. MOOC has no distinction between before, during and after class, so it is impossible to arrange relevant teaching activities, and 
teachers cannot grasp the completion and participation of these activities.

Course teaching requires teachers to master the overall learning situation of specific class. MOOC has no data analysis and processing for the whole class, so teachers cannot grasp the learning progress and learning situation of the whole class in time, nor can they carry out personalized teaching for specific classes. In classroom using MOOC, the means of teaching is monotonous, and activities such as attendance check, questioning and brainstorming cannot be carried out. After the course, registering the grades of the class is also very cumbersome and time-consuming, because of having to query student's grades one by one among so many learners.

MOOC is limited to online learning and cannot carry out practical training. It is more suitable for elective courses for students in school to expand their knowledge, and also suitable for social learners with certain practical experience outside to improve and supplement relevant knowledge and prepare for career growth.

\section{SPOC Are More Suitable for Mixed Teaching}

With the application of MOOC, SPOC (small private online course) has emerged (Yang, 2021). "Small" means that the number of students is limited to dozens to hundreds, while "private" means that joining SPOC is limited. The small-scale SPOC model can effectively provide students with learning resources and formulate more reasonable teaching contents and evaluation rules. Its teaching style mostly adopts the combination of face-to-face classroom and online self-study. It is conducive to teachers' efficient classroom management and personalized teaching to meet learners' needs. Therefore, SPOC is fit for a mixed teaching mode, which transforms MOOC mode into a mode suitable for school teaching (Wei, 2012).

SPOC overcomes the shortcomings of MOOC and is a teaching process innovation based on MOOC. While integrating MOOC's educational thought, SPOC also integrates micro course, minority teaching and intensive education, forming a unique education model. On the SPOC platform, teachers implement mixed teaching, building optimized fragment resources for learners to preview, carrying out classroom teaching interaction, assigning homework and. According to teaching plan, teachers arrange pre class preview on SPOC platform, and set classroom teaching activities according to the key and difficult contents determined in the teaching plan, so as to realize online and offline hybrid teaching.

For SPOC courses, teachers set the score weights of courseware learning, attendance, homework, tests, examinations, classroom questions, brainstorming and other activities. The platform will automatically record the completion of each module for each student. This automatic learning behavior management and accurate big data analysis save teachers a lot of energy and can more accurately grasp the class learning status and learning progress. Teachers give timely praise to students who have a positive learning attitude and complete tasks on 
time; the students with backward learning progress shall be reminded. When the backward students have made significant progress in learning, they shall be given oral praise and positive affirmation in time.

\section{Practical Application of MOOC and SPOC}

In order to carry out mixed teaching, the Intelligent Center of Vocational Education (ICVE) course platform has specially developed the Vocational Education Cloud (VEC) module for mixed teaching, which is very suitable for establishing SPOC courses and carrying out mixed teaching.

According to the different characteristics of MOOC and SPOC, the author has taught several courses for several semesters. For public elective course for the whole school, the course "maintenance of general mechanical equipment" was opened. Because the course is open to all majors in the college and is also open outside the college, so MOOC form was adopted.

For administrative classes in the college or training classes opened outside, the SPOC form has been used and the mixed teaching has been adopted. For SPOC construction, if MOOC has been built, teachers can call MOOC to the Vocational Education Cloud platform. If there is no MOOC built in advance, search for relevant courses in ICVE resource library module or MOOC College (MC) module. Because thousands of courses have been launched in ICVE resource library and MOOC College, these courses can be called for SPOC even if they were not built by teachers. After calling, they can be modified, added and deleted to form courses that meet teaching needs.

In the form of SPOC, the author has carried out mixed teaching of "maintenance of general mechanical equipment", "Fundamentals of mechanical design", "elevator principle and maintenance", and the application effect is good. First of all, the pre class, in class and after class links of Vocational Education Cloud were adopted in the form of classroom teaching. The content of pre class preview, in class learning, classroom activities and after-class exercises were set. Classroom activities include online classroom attendance check using mobile phones, classroom questions, brainstorming, discussion, etc. Teaching forms with SPOC were more interactive. For these teaching activities, SPOC platform will automatically record and evaluate students' scores, and summarize them into the total scores according to their weight. Students can see the scores of individual participation in classroom activities in time, which can be inspired in time. SPOC eliminates the tedious score accounting of teachers. Because SPOC academic performance is calculated as usual performance, students generally pay more attention to it. The class will also demonstrate the overall learning progress data of class students, praising outstanding, encouraging backward, analyzing the shortcomings in learning, and making learning targeted.

\section{Conclusion}

Practice has proved that MOOC can play an important role in changing the tra- 
ditional classroom teaching and learning mode. It can assist students' autonomous learning and reduce teachers' burden, but it also has some limitations. SPOC can build curriculum resources based on MOOC to save teachers' time and energy. SPOC overcomes the shortcomings of MOOC that is not suitable for mixed teaching. It is suitable for combining with the traditional classroom teaching mode to carry out mixed teaching and meet the development requirements of the times.

In order to promote the development of vocational education and improve teaching quality, higher vocational colleges shall take measures to encourage teachers to develop MOOC and SPOC, encourage teachers to use SPOC to promote mixed teaching, reform traditional classroom teaching and keep pace with the times. The traditional supervision method should also be changed for teaching evaluation, and SPOC teaching shall be used as the key index of curriculum teaching evaluation.

\section{Acknowledgements}

This article was funded by the 2019 teaching and scientific research project of Guangzhou Railway Polytechnic (Document No [2019] 12) and the 2019 teaching reform project [JY201926] from Guangdong Higher Vocational Machinery Manufacturing Professional Teaching Steering Committee.

\section{Conflicts of Interest}

The authors declare no conflicts of interest regarding the publication of this paper.

\section{References}

Huo, L. L., Lv, X. Q., Bian, L., \& Guo, X. Y. (2020). Comparative Study on Online Learning Platforms in Online and Offline Hybrid Teaching Mode. Higher Education, 28, 60-61.

Luo, M. (2021). Research on the Value and Limitation of MOOC. Journal of Seeking Knowledge Guide, 4, 8-9.

Peng, X. C., \& Wei, L. (2021). Exploration of Online and Offline Hybrid Teaching of Pathophysiology. Open Journal of Social Sciences, 9, 433-438. https://doi.org/10.4236/jss.2021.99031

Wei, S. P. (2012). An Analysis of Online Learning Behaviors and Its Influencing Factors: A Case Study of Students' Learning Process in Online Course “Open Education Learning Guide" in the Open University of China. Open Education Research, 18, 81-90.

Yang, Y. (2021). A Study on Online Learning Behaviors of the Private University Students Based on SPOC Mode-Take Zhejiang Yuexiu University as an Example. Open Journal of Modern Linguistics, 11, 212-225. https://doi.org/10.4236/ojml.2021.112017

Zhang, H. Y., Zhang, G. L., \& Yu, Y. L. (2020). Research on the Design and Production of Online Course Video in the Age of Converged Media. Open Journal of Social Sciences, 8, 228-233. https://doi.org/10.4236/jss.2020.811021

Zhang, S. J. (2019). Teaching Practice Research on Information Literacy Education Based on MOOC. Journal of Service Science and Management, 12, 126-131. 
https://doi.org/10.4236/jssm.2019.122008

Zhao, F. Y. (2021). Research on the Construction of "Online + Offline" Mixed Teaching Mode of Physical Education in Higher Vocational Colleges. Vocational Technology, 20, 94-98.

Zhi, Y., \& Yang, G. H. (2019). Research and Practice of Mixed Teaching in the Course of Electrical Engineering and Electronics. Open Access Library Journal, 6, e5890. https://doi.org/10.4236/oalib.1105890

Zhong, Z. X. (2005). Research on Design of Learning Environment. e-Education Research, No. 7, 35-41.

Zulkifli, N., Hamzah, M. I., \& Bashah, N. H. (2020). Challenges to Teaching and Learning Using MOOC. Creative Education, 11, 197-205. https://doi.org/10.4236/ce.2020.113014 